\title{
SIMULATION AND OPTIMIZATION-BASED APPROACHES TO ASSESS THE BEHAVIOUR OF THE RETAIL SUPPLY CHAIN NETWORK DESIGNS
}

\author{
*Inoka Munasinghe ${ }^{1}$ and *Thashika Rupasinghe ${ }^{2}$ \\ *Department of Industrial Management, Faculty of Science, University of Kelaniya, Sri Lanka
}

\begin{abstract}
The study focuses on using optimization and simulation-based modeling approaches to evaluate the performance to assess the viability of a Supply Chain Network Design (SCND). It enables companies to perform powerful what-if analyses leading them to make better informed decisions. The study helps companies evaluate the appropriate number, location and necessary capacities of their distribution centres (DCs) and warehouses based on projected demand and service level targets. This allows the decision makers to see the performance of the supply chain over time under various scenarios and assist them to understand the inter-relationships between different modeling components. The authors have using retail supply chains as a test bed and carried out performance evaluation under various scenarios to enhance the applicability of the SCND by varying locations, number of facilities and product combinations. The ultimate objectives of the work were to minimize total supply chain network design cost including variable cost and maximize organization's customer service potential and provides a comprehensive analysis of the firm's supply chain structure and performance through pre-defined set of scenarios.
\end{abstract}

Keywords: exact mathematical approaches; multi-echelon optimization; simulation; supply chain network design

\section{Introduction}

A world class transformational supply chain begins with a network that employs an all-encompassing view of the various business areas that manage the delivery of products to customers. The result is significant capital, operational, and tax savings while achieving optimal customer satisfaction. An increasing number of companies are asking the question: "How can my supply chain be used to maximize profits?" This is a different objective than traditional network optimization projects which define the objective as reducing costs and maintaining customer service levels. Therefore, with the current identification, maximizing profit through the supply chain network is mainly focused and attractive area in the competitive business world.

The network design problem is one of the most comprehensive strategic decision problems that need to be addressed for a long-term efficient operation of the entire supply chain. The SCND provides an optimal platform for efficient and effective supply chain management (Varasteh, 2007). In addition to that, it determines the number, location, capacity and type of plants, warehouses and DCs to be used (Altiparmak et al, 2006). Although there are many studies have been done on supply chain network optimization, there are only few significant studies carried out in linking with a distribution network design optimization and supply chain network.

As pointed by, Keizer et al, (2012), there is a need, and a challenge, to incorporate the deterioration of product quality in both design and control models. Simulation is a powerful technique to model detailed product characteristics as well as logistical control processes. Optimization techniques are able to produce new network scenarios and to optimize the flow of products throughout the network. A hybrid

Corresponding Authors: ${ }^{1}$ inokaudayangi221@gmail.com, ${ }^{2}$ thashika@kln.ac.lk 
approach combining simulation and optimization is a promising research direction.

Though the most of the real world scenarios are involved with multi-product, multi-stage and multisource approach, most of the studies haven't focused these scenarios together. So, the study is considered this all scenarios together by performing IBM CPLEX® and compared performance with simulation. Since the supply chain network design decisions are strategic, it should be optimal. So, the solving mechanism should be given the optimal solution approach. Therefore, CPLEX optimal solution is the best answer for analyzing the supply chain network.

Retail is the final stage of any economic activity. By virtue of this fact retail occupies an important place in the world economy. In the current business context, retail industries have growing demand than the other industries. In result, by blending with the optimize supply chain network retail distributors can gain competitive advantage than the rivals. Furthermore, this study supports to the decision making process on strategic planning to design and control many real world complex practical scenarios.

The remainder of this paper is organized as follows. The literature review is described in next section. Thereafter, study describes methodology and results and discussion. Conclusions are presented in last section.

\section{Literature review}

According to the Ambrosino and Scutella, (2005), while analyzing a distribution network, two factors can be distinguished such as the optimization of the flows of goods: in this case it is considered an existing distribution network, and need to optimize the flows of goods through the network; and the improvement of the existing network: in this case need to choose the best configuration of the facilities in the network in order to satisfy the goals of the company, while minimizing the overall costs. There are extensive literatures available on the analysis of supply chain coordination. Two of the most common ways of analyzing a supply chain are simulation and analytical modeling. Therefore, this study is focused with hybrid approach by combining optimization and simulation.

Truong and Azadivar, (2003) has considered about the simulation based optimization for supply chain configuration design. His new approach combines simulation, mixed integer programming and genetic algorithm. The simulation model returns the overall long run system-wide cost and customer service level of the supply chain. Reiner and Trcka, (2004) have studied a product-specific supply chain in the food industry, analyzes the effects of changes carried out and shows how demand uncertainties are dealt with. To measure and analyze the performance effects of the supply chain configuration alternatives depicted, a simulation environment has developed.

Simulation modeling and analysis has become a popular technique for analyzing the effects of these changes without actual implementation or assignment of resources. Many manufacturing systems can be easily and adequately analyzed with discrete event simulation models. However, other systems may require more complex continuous event or even combined discrete and continuous event simulation approaches in order to develop valid models (Huda and Chung, 2002).

Al-Zubaidi and Tyler, (2004), Simulation modelling work has been undertaken to gain insights into the dynamic behavior of apparel supply to retail customers. In particular, this research has looked at replenishment strategies in response to consumer demand. From an operations research point of view, Supply Chain Network Design (SCND) is the discipline used to determine the optimal location and size of facilities and the flow through the facilities (Goldsby et al, 2013). As recalled in Farahani et al, (2014), there are many models in the SCND literature. Different decisions are made in the SCND and perhaps the most critical one is locating the facilities in different tiers of the supply chain. Thus this study is focused to fill the gap of the current literature by providing the solution for distributing products with minimum distribution cost.

As the literature, most of the optimization models are limited for single stage or two stages and as pointed 
by Munasinghe and Rupasinghe, (2016), though the distance is playing a major role with supply chain network design cost, most of the studies have not focused distance for calculating the distribution network cost. Furthermore, it's hard to find the optimization and simulation combined approach with multi echelon supply chain network design with current literature and it has proved by Table 1 which is elaborated by Munasinghe and Rupasinghe, (2016).

Table 1:Summary of the systematic review (Source: Munasinghe and Rupasinghe, (2016)

\begin{tabular}{|c|c|c|c|c|c|}
\hline Study & Application Area & Decision Variables & $\begin{array}{l}\text { Number } \\
\text { of } \\
\text { Stages }\end{array}$ & $\begin{array}{l}\text { Multi- } \\
\text { Product }\end{array}$ & $\begin{array}{l}\text { Multi- } \\
\text { Source }\end{array}$ \\
\hline $\begin{array}{l}\text { Altiparmak et } \\
a l,(2006)\end{array}$ & $\begin{array}{l}\text { The model aims to select the } \\
\text { suppliers, determine the subsets } \\
\text { of plants and DCs to be opened } \\
\text { and design the distribution } \\
\text { network strategy that will satisfy } \\
\text { all capacities and demand } \\
\text { requirement for the product } \\
\text { imposed by customers }\end{array}$ & $\begin{array}{l}\text { The quantity of raw } \\
\text { material shipped from } \\
\text { supplier to plant } \\
\text { The quantity of the } \\
\text { product shipped from } \\
\text { plant to DC and DC to } \\
\text { customer }\end{array}$ & Three & & $x$ \\
\hline $\begin{array}{l}\text { Keskin and } \\
\text { Uster, (2007) }\end{array}$ & $\begin{array}{l}\text { The model determines where to } \\
\text { locate DCs and how many of } \\
\text { each product to be transported } \\
\text { from plants to DCs and from } \\
\text { DCs to retailers in such a way } \\
\text { that the total fixed location costs } \\
\text { and transportation costs in the } \\
\text { system are minimized }\end{array}$ & $\begin{array}{l}\text { Number of products } \\
\text { transported from DC to } \\
\text { customer } \\
\text { Number of product } \\
\text { transported from plant } \\
\text { to DC }\end{array}$ & Two & $x$ & $x$ \\
\hline $\begin{array}{l}\text { Altiparmak et } \\
a l,(2009)\end{array}$ & $\begin{array}{l}\text { Determines the subsets of plants } \\
\text { and DCs to be opened and to } \\
\text { design the distribution network } \\
\text { strategy that will satisfy all } \\
\text { capacities and demand } \\
\text { requirements for each product } \\
\text { requested by the customer at a } \\
\text { minimum cost }\end{array}$ & $\begin{array}{l}\text { The quantity of raw } \\
\text { material shipped from } \\
\text { supplier to plant } \\
\text { The quantity of the } \\
\text { product shipped from } \\
\text { plant to DC and DC to } \\
\text { customer }\end{array}$ & Three & & $x$ \\
\hline $\begin{array}{l}\text { Golmohammadi } \\
\text { et al, (2010) }\end{array}$ & $\begin{array}{l}\text { Determines the optimal } \\
\text { distributing strategy from the } \\
\text { plants to the warehouses and } \\
\text { from the warehouses to the } \\
\text { customers }\end{array}$ & $\begin{array}{l}\text { Quantity of demand } \\
\text { from customer zone } \\
\text { delivered from } \\
\text { warehouse } \\
\text { Shipments from plant to } \\
\text { warehouse }\end{array}$ & Two & & $x$ \\
\hline $\begin{array}{l}\text { Machado et al, } \\
\text { (2016) }\end{array}$ & $\begin{array}{l}\text { Determines the set of DCs to be } \\
\text { open so that the company can } \\
\text { fully meet the demands of its } \\
\text { customers at the lowest possible } \\
\text { cost }\end{array}$ & $\begin{array}{c}\text { Quantity of product } \\
\text { shipped from factory to } \\
\text { DC } \\
\text { Quantity of raw material } \\
\text { shipped from vendor to } \\
\text { factory }\end{array}$ & Three & $x$ & \\
\hline
\end{tabular}


According to the literature, most of the studies are limited to single source, single product and single stage approach. Furthermore, the distribution network design has gained a very limited consideration.
Therefore, the authors have considered the multiechelon supply chain network design as the test bed to optimize the distribution cost. Summary of the literature is depicted in Table 2.

Table 2 Summary of the modeling approaches literature review

\begin{tabular}{|c|c|c|}
\hline Title & Study & Description of the modeling approach \\
\hline $\begin{array}{l}\text { Simulation based optimization for } \\
\text { supply chain configuration design }\end{array}$ & $\begin{array}{l}\text { Truong and Azadivar, } \\
\text { (2003) }\end{array}$ & $\begin{array}{l}\text { Develop a hybrid optimization approach to } \\
\text { address the Supply Chain Configuration } \\
\text { Design problem. The new approach combines } \\
\text { simulation, mixed integer programming and } \\
\text { genetic algorithm }\end{array}$ \\
\hline $\begin{array}{l}\text { Customized supply chain design: } \\
\text { Problems and alternatives for a } \\
\text { production company in the food } \\
\text { industry. A simulation based } \\
\text { analysis }\end{array}$ & Reiner and Trcka, (2004) & $\begin{array}{c}\text { Suggest an improvement model that helps } \\
\text { enhance the performance of a specific supply } \\
\text { chain }\end{array}$ \\
\hline $\begin{array}{l}\text { Simulation modeling and analysis } \\
\text { issues for high-speed combined } \\
\text { continuous and discrete food } \\
\text { industry manufacturing processes }\end{array}$ & Huda and Chung, (2002) & $\begin{array}{c}\text { Illustrate some of the issues associated with a } \\
\text { real world example of a combined continuous } \\
\text { and discrete event high-speed food } \\
\text { processing simulation model }\end{array}$ \\
\hline $\begin{array}{l}\text { Simulation of Supply-Chain } \\
\text { Networks: A Source of Innovation } \\
\text { and Competitive Advantage for } \\
\text { Small and Medium-Sized } \\
\text { Enterprises }\end{array}$ & Liotta, (2012) & $\begin{array}{c}\text { Emphasize the relevance of simulation for the } \\
\text { design and management of supply-chain } \\
\text { networks from the perspective of small and } \\
\text { medium-sized firms }\end{array}$ \\
\hline $\begin{array}{l}\text { Simulation modelling for food } \\
\text { supply chain redesign; Integrated } \\
\text { decision making on product } \\
\text { quality, sustainability and logistics }\end{array}$ & $\begin{array}{l}\text { van der Vorst et al, } \\
\text { (2009) }\end{array}$ & $\begin{array}{l}\text { Propose a new integrated approach towards } \\
\text { logistics, sustainability and food quality } \\
\text { analysis, and implement the approach by } \\
\text { introducing a new simulation environment }\end{array}$ \\
\hline $\begin{array}{l}\text { Optimizing Coordination Strategies } \\
\text { in a Real Supply Chain: Simulation } \\
\text { Approach }\end{array}$ & Ingenieur, (2007) & $\begin{array}{l}\text { Develop new coordination distribution } \\
\text { strategies that coordinate the inventory and } \\
\text { transportation activities and optimize the } \\
\text { performance of the supply chain. }\end{array}$ \\
\hline
\end{tabular}

\section{Methodology}

The study focuses on optimizing the retail supply chain network design cost with hybrid optimization and simulation approach. As the methodology, first and foremost the study is come up with a literature survey to find out the approaches and gaps of the network design model development by Munasinghe and Rupasinghe, (2016).With that model development authors have come up with new mathematical approach to minimize the total SCND existing literature related to supply chain network. Through the literature survey identified the current need for the optimization-simulation approach with supply chain network design.

In this study, the authors use an optimizationsimulation based approach on the latest supply chain cost considering in a multi-echelon network where multi suppliers, multi, warehouses, multi, DCs, multi retailer, and multi products are taken into consideration and the model is depicted in below. 


$$
\begin{gathered}
\sum_{i=1}^{I} \sum_{j=1}^{J} \sum_{x=1}^{X} c_{i j x} Q 1_{x i j} d_{i j}+\sum_{j=1}^{J} \sum_{k=1}^{K} \sum_{x=1}^{X} c_{j k x} Q 2_{x j k} d_{j k}+\sum_{k=1}^{K} \sum_{l=1}^{L} \sum_{x=1}^{X} c_{k l x} Q 3_{x k l} d_{k l} \\
+\sum_{i=1}^{L} \sum_{l=1}^{L} \sum_{x=1}^{X} c_{i l x} Q 4_{x i l} d_{i l}+\sum_{i=1}^{L} \sum_{k=1}^{K} \sum_{x=1}^{X} c_{i k x} Q 5_{x i k} d_{i k} \\
+\sum_{j=1}^{J} \sum_{l=1}^{L} \sum_{x=1}^{X} c_{j l x} Q 6_{x j l} d_{j l}
\end{gathered}
$$

[Source: Munasinghe and Rupasinghe, 2016]

To evaluate this model, some numerical analysis was conducted using the CPLEX solver with RSC literature test cases and presented performance analysis with simulation. The study approach is depicted in Figure 1.

The methodology of this study is focused on determining the most profitable combination of supplier-warehouse-DC-retail mapping for product flow combinations. As depicted in the figure 1, optimization is performed through IBM CPLEX® software and what-if analyses were performed through the simulation approach using the Supply Chain Guru® software. Considered supply chain network design is depicted in Figure 2.

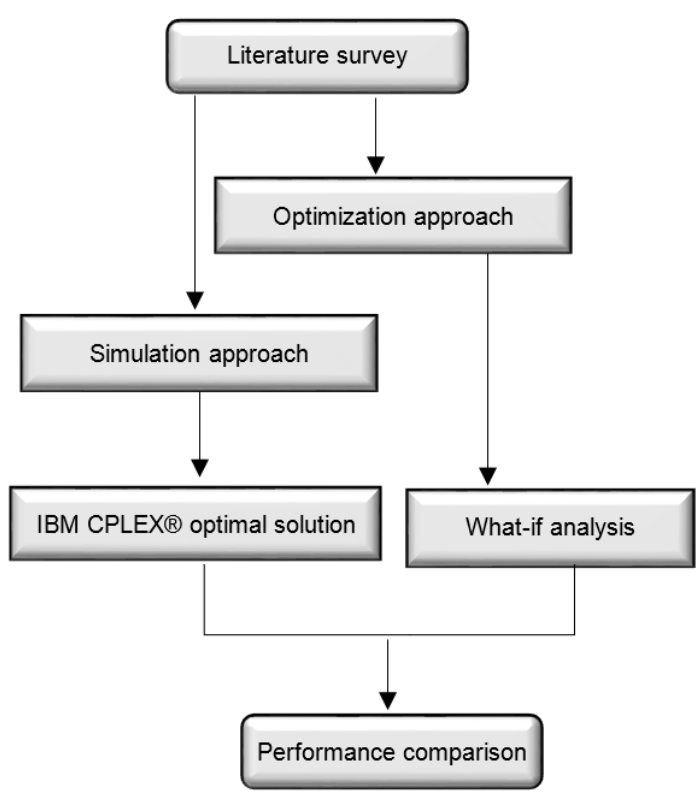

Figure 1 Research methodology of the simulation and optimization-based approach

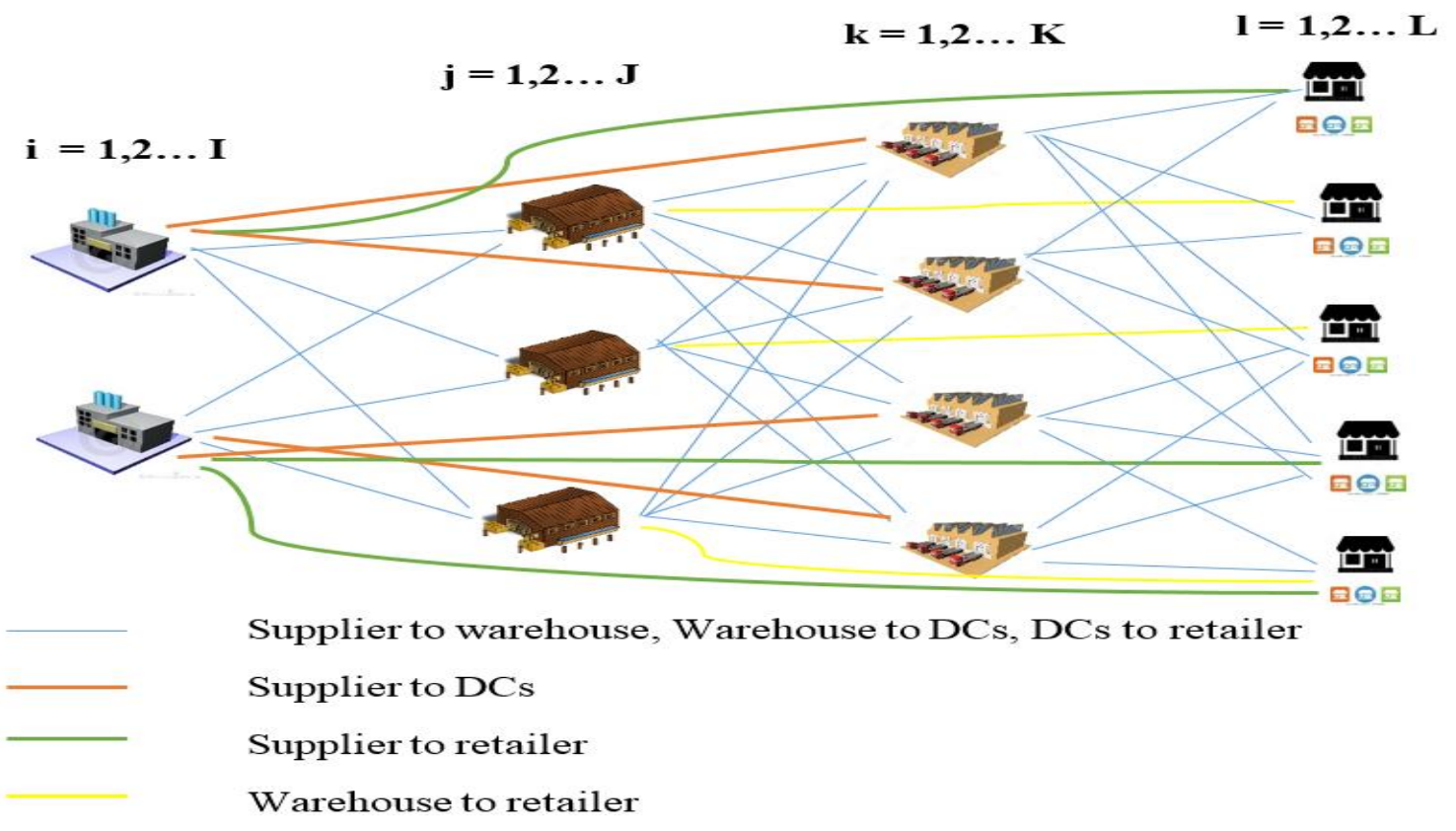

Figure 2 Supply chain network design 


\section{Results and discussion}

\section{Simulation-based Approach}

Computer simulation is an especially effective tool to help investigate and analyze complex problems. Because it can be applied to operational problems that are too difficult to model and solve analytically. Moreover, mathematical models require too many simplifications and assumptions to model coordination strategies in realistic supply chain problems. Discrete event simulation permits complex logistics systems to be modeled more realistically (Terzi and Cavalieri, 2004). Therefore. The authors are focused with simulation model to perform the powerful what-if analyses with Supply Chain Guru®. It has considered the six main model elements to develop the simulated network design such as product, site, demand, inventory policies, transportation policies and sourcing policies. These elements combine to provide the nodes of the network, the links between the nodes, and the relationships created by these links.
Rupasinghe, (2016). As discussed in the methodology, this is used to analyze the behavior of supply chain network design which is then optimized using IBM CPLEX® optimal solution.

As explained in Ding et al, (2007), it has been stated that optimization is hardly used independently in industries. Comparing to optimization techniques, simulation is more suitable for the evaluation of complex industrial systems given a limited number of candidate scenarios. Also, it's provided answer for deciding that if it is changed the network design, how it will influence the performance of the supply chain network. Also, it can be used to analyze the single sourcing and multi-sourcing influence for the SCND. Not only that but also it is supported to analyze the facility variation with demand.

This simulation is evaluated through 16 different kind of scenarios. Data table is depicted in Table 3.

S- Supplier, W- Warehouse, DC- Distribution Centre, R- Retailer, X- Products

Table 3 Data of the simulation analysis

\begin{tabular}{|c|c|c|c|c|c|c|c|c|}
\hline \multicolumn{9}{|c|}{ Number of facilities } \\
\hline & \multicolumn{4}{|c|}{ Single facility consideration } & \multicolumn{4}{|c|}{ Multi facility consideration } \\
\hline & $\begin{array}{c}\text { Single } \\
\text { supplier }\end{array}$ & $\begin{array}{c}\text { Single } \\
\text { warehouse }\end{array}$ & $\begin{array}{c}\text { Single } \\
\text { DC }\end{array}$ & $\begin{array}{l}\text { Single } \\
\text { retailer }\end{array}$ & $\begin{array}{c}\text { Multi } \\
\text { supplier }\end{array}$ & $\begin{array}{c}\text { Multi } \\
\text { warehouse }\end{array}$ & $\begin{array}{c}\text { Multi } \\
\text { DC }\end{array}$ & $\begin{array}{l}\text { Multi } \\
\text { retailer }\end{array}$ \\
\hline Single product & $\begin{array}{c}\mathrm{S}=1, \\
\mathrm{~W}=3, \\
\mathrm{DC}=4, \\
\mathrm{R}=13\end{array}$ & $\begin{array}{c}\mathrm{S}=2, \\
\mathrm{~W}=1, \\
\mathrm{DC}=4, \\
\mathrm{R}=13\end{array}$ & $\begin{array}{c}\mathrm{S}=2, \\
\mathrm{~W}=3, \\
\mathrm{DC}=1, \\
\mathrm{R}=13\end{array}$ & $\begin{array}{c}\mathrm{S}=2, \\
\mathrm{~W}=3, \\
\mathrm{DC}=4, \\
\mathrm{R}=1\end{array}$ & $\begin{array}{c}\mathrm{S}=3, \\
\mathrm{~W}=3, \\
\mathrm{DC}=4, \\
\mathrm{R}=13\end{array}$ & $\begin{array}{c}\mathrm{S}=2, \\
\mathrm{~W}=4, \\
\mathrm{DC}=4, \\
\mathrm{R}=13\end{array}$ & $\begin{array}{c}S=2, \\
W=3, \\
D C=5, \\
R=13\end{array}$ & $\begin{array}{r}\mathrm{S}=2, \\
\mathrm{~W}=3, \\
\mathrm{DC}=4, \\
\mathrm{R}=14\end{array}$ \\
\hline Multi product & $\begin{array}{c}S=1, \\
W=3, \\
D C=4, \\
R=13\end{array}$ & $\begin{array}{c}\mathrm{S}=2, \\
\mathrm{~W}=1, \\
\mathrm{DC}=4, \\
\mathrm{R}=13,\end{array}$ & $\begin{array}{c}\mathrm{S}=2, \\
\mathrm{~W}=3, \\
\mathrm{DC}=1, \\
\mathrm{R}=13\end{array}$ & $\begin{array}{c}\mathrm{S}=2, \\
\mathrm{~W}=3, \\
\mathrm{DC}=4, \\
\mathrm{R}=1\end{array}$ & $\begin{array}{c}\mathrm{S}=3 \\
\mathrm{~W}=3 \\
\mathrm{DC}=4 \\
\mathrm{R}=13\end{array}$ & $\begin{array}{c}\mathrm{S}=2, \\
\mathrm{~W}=4, \\
\mathrm{DC}=4, \\
\mathrm{R}=13\end{array}$ & $\begin{array}{c}S=2, \\
W=3, \\
D C=5, \\
R=13\end{array}$ & $\begin{array}{c}\mathrm{S}=2, \\
\mathrm{~W}=3, \\
\mathrm{DC}=4, \\
\mathrm{R}=14\end{array}$ \\
\hline
\end{tabular}

According to the above data table scenarios have been created to run the simulations and the total cost obtained is depicted as comparison to the base-case scenario. This is depicted in Table 4 and profit

The simulation-based scenarios have been created using the model developed by Munasinghe and comparison depicted in Table 5. 
Table 4 Simulated model results for cost

\begin{tabular}{lcc}
\hline Scenario & \multicolumn{1}{c}{ Total cost } & \multirow{2}{*}{ Changed cost percentage } \\
\cline { 1 - 2 } Baseline scenario & $2,350,873,446.7150$ & $-10.47 \%$ \\
\hline Single product- Single supplier & $2,104,684,982.9513$ & $-3.45 \%$ \\
\hline Single product- Single warehouse & $2,269,540,167.1588$ & $-17.34 \%$ \\
\hline Single product- Single DC & $1,943,066,302.1636$ & $-93.21 \%$ \\
\hline Single product- Single retailer & $159,738,869.6922$ & $-8.86 \%$ \\
\hline Multi product- Single supplier & 2142446900.2794 & $-2.11 \%$ \\
\hline Multi product- Single warehouse & $2,301,039,520.5871$ & $-16.16 \%$ \\
\hline Multi product- Single DC & $1,970,801,887.5816$ & $-93.20 \%$ \\
\hline Multi product- Single retailer & $159,738,869.6922$ & $-9.04 \%$ \\
\hline Single product- Multi supplier & $2,138,298,804.9216$ & $-4.96 \%$ \\
\hline Single product- Multi warehouse & $2,234,326,486.5906$ & $-4.95 \%$ \\
\hline Single product- Multi DC & $2,234,593,270.5906$ & $-2.82 \%$ \\
\hline Single product- Multi retailer & $2,284,470,489.2035$ & $-8.95 \%$ \\
\hline Multi product- Multi supplier & 2140428720.9216 & $-4.79 \%$ \\
\hline Multi product- Multi warehouse & $2,238,283,354.3906$ & $-4.77 \%$ \\
\hline Multi product- Multi DC & $2,238,771,559.5906$ & $-2.61 \%$ \\
\hline Multi product- Multi retailer & $2,289,478,489.2035$ & \\
\hline
\end{tabular}

Table 5 Simulated model results for profit

\begin{tabular}{lcc}
\hline Scenario & \multicolumn{1}{c}{ Total profit } & \multirow{2}{*}{ Changed profit percentage } \\
\cline { 1 - 2 } Baseline scenario & $2,625,244,073.2850$ & \\
\hline Single product- Single supplier & $2,871,432,537.0487$ & $9.38 \%$ \\
\hline Single product- Single warehouse & $2,706,577,352.8412$ & $3.09 \%$ \\
\hline Single product- Single DC & $3,033,051,217.8364$ & $15.53 \%$ \\
\hline Single product- Single retailer & $41,792,130.3078$ & $-98.41 \%$ \\
\hline Multi product- Single supplier & $2,904,539,119.7206$ & $10.63 \%$ \\
\hline Multi product- Single warehouse & $2,736,856,499.4129$ & $4.25 \%$ \\
\hline Multi product- Single DC & $3,062,857,132.4184$ & $16.66 \%$ \\
\hline Multi product- Single retailer & $41,999,890.3078$ & $-98.40 \%$ \\
\hline Single product- Multi supplier & $2,837,818,715.0784$ & $8.09 \%$ \\
\hline Single product- Multi warehouse & $2,739,448,033.4094$ & $4.35 \%$ \\
\hline Single product- Multi DC & $2,739,049,249.4094$ & $4.33 \%$ \\
\hline Single product- Multi retailer & $2,816,964,530.7965$ & $7.30 \%$ \\
\hline Multi product- Multi supplier & $2,844,372,799.0784$ & $8.34 \%$ \\
\hline Multi product- Multi warehouse & $2,744,721,365.6094$ & $4.55 \%$ \\
\hline Multi product- Multi DC & $2,743,871,960.4094$ & $4.51 \%$ \\
\hline Multi product- Multi retailer & $2,828,964,930.7965$ & $7.76 \%$ \\
\hline
\end{tabular}


Simulation-based approach is enhanced the understandability of the SCND behavior by applying multi-product and single product scenarios with multiple facility combinations in separately. Thus, it is easy to carry out a performance analysis and interpret the appropriate supplier to retail mapping with different kinds of products.
When compared with the baseline scenario, multiproducts with single DC scenario gives the highest profit. Furthermore, it is evident that this can be used to evaluate each different scenario and take managerial strategic decisions. The Supply Chain Guru ${ }^{\circledR}$, profit comparison is depicted as in Figure 3 and total cost comparison is depicted in Figure 4.

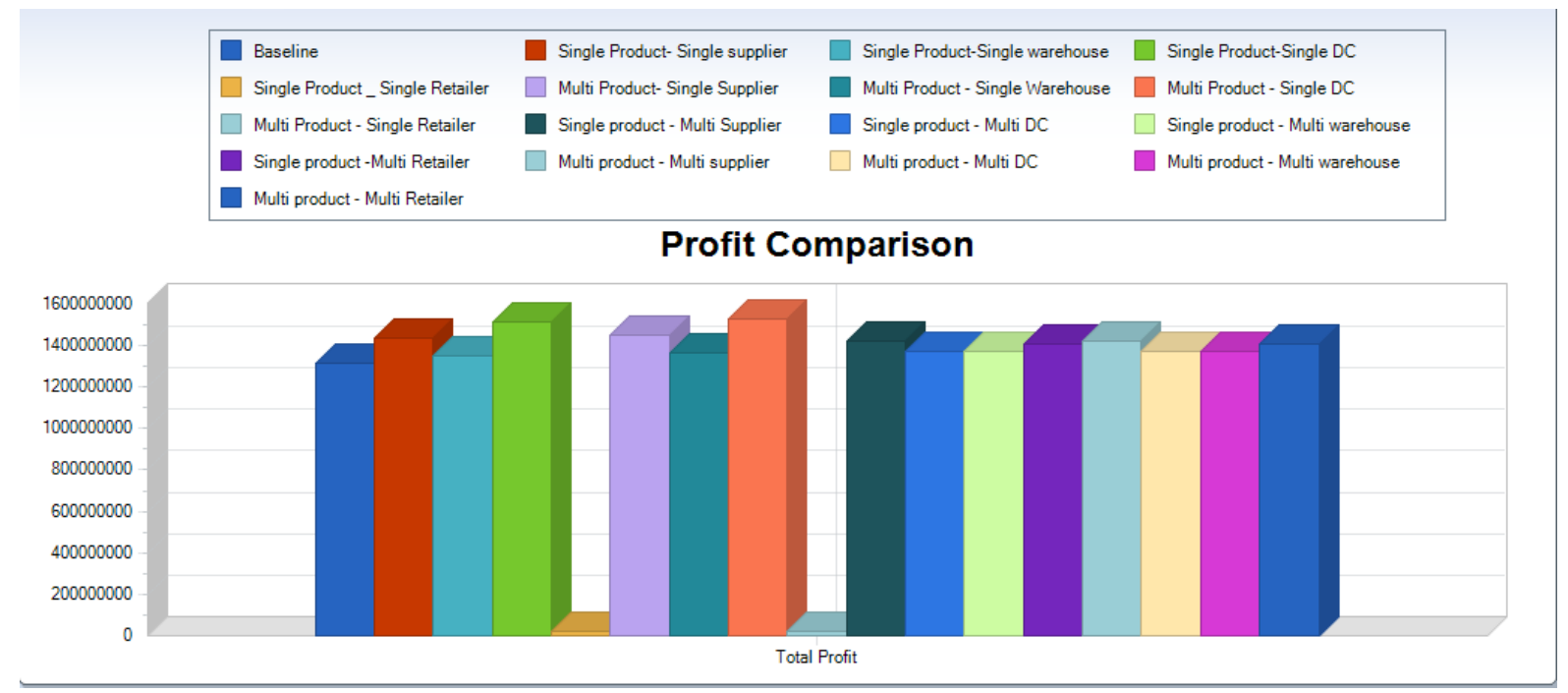

Figure 3 Profit comparison of the simulated model

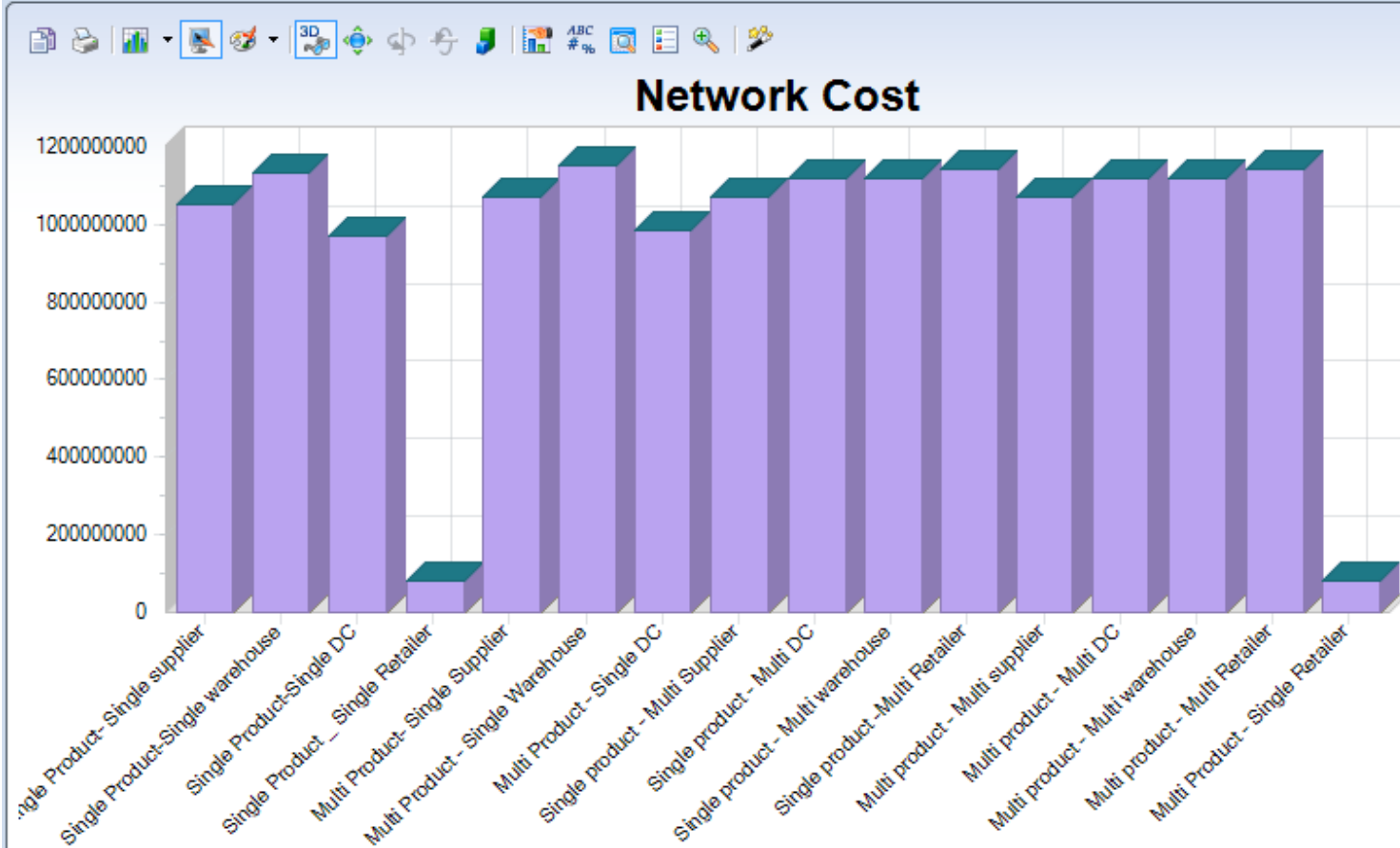

Figure 4 Cost comparison of the simulated model 
Finally, it can be concluded that the above simulation approach supports the strategic decision making on a typical SCND. It supports the performance evaluation of the designed network and the scenarios well explain the multi-product, multi-echelon, multisource, multi-stage SCND by providing better inner visibility to the supply chain network.

\section{Optimization-based Approach}

In the present competitive era, logistics and supply chain network plays a vital role towards the economic growth of a country (Biswas and Samanta, 2016). IBM CPLEX optimal solution is a state-of-the-art software tool which provides the ability to solve any complex Mixed Integer Programming (MIP) formulation optimally with a reasonable time.
The SCND decisions are strategic decisions and most of the cases optimal solution plays an important role. By using the IBM CPLEX toolkit the optimal solutions were found with the most profitable supplier-warehouse-DC-retailer mapping for product flows. However, the obstacle is, the execution time of CPLEX increases with the problem size. However, finding an optimal solution is important for the strategic decisions as those decisions can't be dynamically changed. This study utilizes the IBM CPLEX solver for solving the optimal design with respect to different scenarios as depicted in the Table 6. Due to the long the execution times, the comparison analysis only considers small size problems and this sample problems are formulated taking inside from real world business scenarios.

Table 6 Sample scenarios with different dimensions

\begin{tabular}{lccccc}
\hline Sample problem & Supplier & Warehouse & DC & Retailer & Products \\
\hline 1 & 2 & 2 & 2 & 3 & 3 \\
\hline 2 & 2 & 1 & 3 & 4 & 3 \\
\hline 3 & 2 & 1 & 2 & 5 & 3 \\
\hline 4 & 1 & 2 & 2 & 4 & 3 \\
\hline 5 & 1 & 2 & 3 & 5 & 3 \\
\hline 6 & 1 & 2 & 3 & 6 & 3 \\
\hline 7 & 2 & 2 & 2 & 4 & 4 \\
\hline 8 & 2 & 1 & 3 & 5 & 4 \\
\hline 9 & 2 & 1 & 2 & 4 & 4 \\
\hline 10 & 1 & 2 & 2 & 5 & 4 \\
\hline 11 & 1 & 2 & 3 & 6 & 4 \\
\hline 12 & 1 & 2 & 3 & 4 \\
\hline
\end{tabular}

According to the sample problems, the study is carried out by changing number of facilities and number of products to find the optimal solution. Furthermore, this sample problems help to understand the network design and analyze performance with different cases to design the network as profitable way.
Developed CPLEX solution pseudo code is depicted in Figure 5 and Figure 6. 


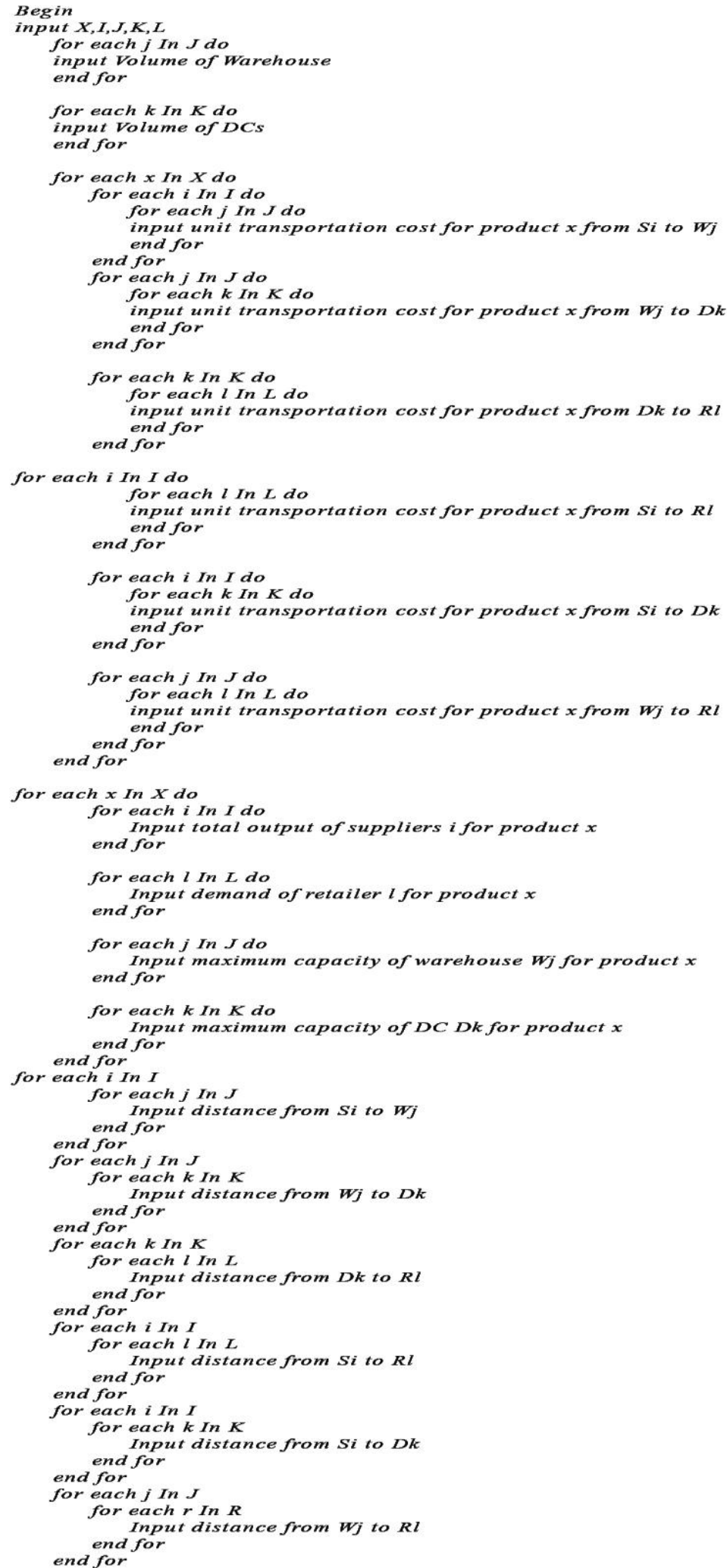

Figure 5 CPLEX solution pseudo code part 1 


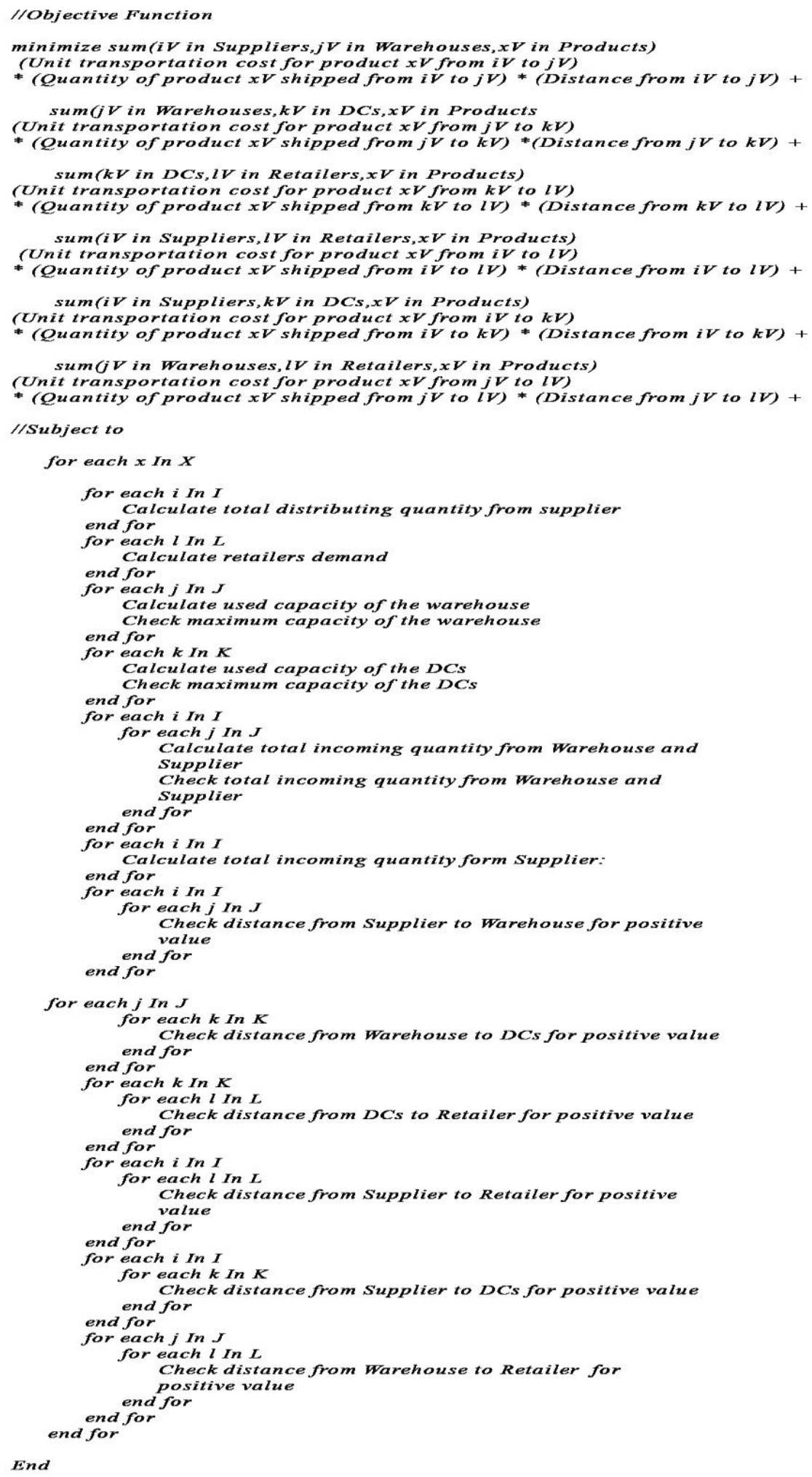

Figure 6 CPLEX solution pseudo code part 2 
By using the above pseudo code, the optimal solution results which are obtained from IBM CPLEX are depicted in Table 7. As explained before the execution time increased as the size of the problem increases.

Table 7 Result of the CPLEX optimal solution

\begin{tabular}{lcc}
\hline Sample Problem & No. of variables & Optimal solution \\
\hline 01 & 90 & $11,520,880$ \\
\hline 02 & 105 & $19,248,380$ \\
\hline 03 & 99 & $33,589,850$ \\
\hline 04 & 84 & $14,755,220$ \\
\hline 05 & 123 & $18,655,860$ \\
\hline 06 & 141 & $20,331,350$ \\
\hline 07 & 120 & $16,713,430$ \\
\hline 08 & 140 & $26,237,330$ \\
\hline 09 & 132 & $48,681,050$ \\
\hline 10 & 112 & $26,362,970$ \\
\hline 11 & 164 & $32,202,610$ \\
\hline 12 & 188 & $34,942,930$ \\
\hline
\end{tabular}

\section{Conclusions}

The level of competitiveness across all industrial sectors has increased in the last few years due to the globalization. This increased level of competitiveness is pushing companies to achieve further optimization of their business processes and particularly to collaborate with their direct logistics entities in supply chain network. Therefore, this study yields the need of using optimization and simulation-based approaches to better understand supply chain networks.

Though the SCND have been thoroughly researched in the literature, most of the cases have ignored the multi-echelon SCND approach. In this study the authors' review, optimization and simulation-based approaches and how these approaches be used in assessing dynamics of the supply chain behavior. The literature belongs to either optimization or simulation. A few of the studies have explored hybrid methods which include both optimization and simulation together. However, most of the studies have not examined multi-product, multi-stage and multi-source considerations together in order to minimize the total distribution network cost. Furthermore, multi-echelon supply chain network design considerations have filled the gap in this domain as pointed by Munasinghe and Rupasinghe, (2016). Therefore, this paper presents an optimization and simulation approach to capture and design the real scenario of retail supply chain network design with multiproduct, multi-source.

With optimization approach alone, ignores the behavior of the network design and simulation modelling facilitates to evaluate the performance of the supply chain network design much more dynamic nature. With the exact mathematical modelling approach the solution yielded through CPLEX, provides the optimal network design and the quantities to be transferred from facility to facility while minimizing the total distribution network cost. Furthermore, simulation analysis supports the evaluation of the behavior of supply chain network design.

Finally, this study is more beneficial for strategic decisions with respect to retail supply chain networks 
and the numerical analyses are carried out for smallsized problem instances. Therefore, future studies can be proposed to alleviate this limitation to better assess

\section{References}

Altiparmak, F., Gen, M., Lin, L. and Paksoy, T. (2006). A genetic algorithm approach for multiobjective optimization of supply chain networks. Computers \& Industrial Engineering, 51(1), pp.196215.

Altiparmak, F., Gen, M., Lin, L. and Karaoglan, I. (2009). A steady-state genetic algorithm for multiproduct supply chain network design. Computers \& Industrial Engineering, 56(2), pp.521-537.

Al-Zubaidi, H. and Tyler, D. (2004). A simulation model of quick response replenishment of seasonal clothing. International Journal of Retail \& Distribution Management, 32(6), pp.320-327.

Ambrosino, D. and Scutella, M. (2005). Distribution network design: New problems and related models. European Journal of Operational Research, 165, pp.610-624.

Biswas, T. and Samanta, S. (2016). A strategic decision support system for logistics and supply chain network design. Indian Academy of Sciences, 41(06), pp.583-588.

Ding, H., Wang, W. and Dong, J. (2007). IBM supply-chain network optimization workbench: An integrated optimization and simulation tool for supply chain design. In: Winter Simulation. IEEE.

Farahani, R., Rezapour, S., Drezner, T. and Fallah, S. (2014). Competitive supply chain network design: An overview of classifications, models, solution techniques and applications. Omega, 45, pp.92-118.

Goldsby, A., Bell, J., Moon, M., Munson, C., Watson, M., Lewis, S., Cacioppi, P. and Jayaraman, J. (2013). The Denitive Guide to Modern Supply Chain Management (Collection. Pearson Education.

Golmohammadi, V., Afshari, H., Hasanzadeh, A. and Rahiml, M. (2010). A heuristic approach for designing a distribution network in a supply chain system. African Journal of Business Management, 4(3), pp.308-311.

Huda, A. and Chung, C. (2002). Simulation modeling and analysis issues for high-speed combined continuous and discrete food industry manufacturing processes. Computers \& Industrial Engineering, 43(3), pp.473-483.

Ingenieur, D. (2007). Optimizing Coordination Strategies in a Real Supply Chain: Simulation Approach. genehmigte. Duisburg-Essen. a much more generalized multi-echelon supply chain networks.

Keizer, M., Haijema, R., Vorst, J. and BloemhofRUWAARD, J. (2012). Hybrid simulation and optimization approach to design and control fresh product networks. In: Winter Simulation Conference. pp.1143-1154.

Keskin, B. and Üster, H. (2007). Meta-heuristic approaches with memory and evolution for a multiproduct production/distribution system design problem. European Journal of Operational Research, 182(2), pp.663-682.

Liotta, G. (2012). Simulation of Supply-Chain Networks: A Source of Innovation and Competitive Advantage for Small and Medium-Sized Enterprises. Technology Innovation Management Review, (November: Insights), pp.13-20.

Machado Braido, G., Borenstein, D. and Casalinho, G. (2016). Supply chain network optimization using a Tabu Search based heuristic. São Carlos, 23(1), pp.03-17.

Munasinghe, I. and Rupasinghe, T. (2016). A supply chain network design optimization model from the perspective of a retail distribution supply chain. In: Manufacturing \& Industrial Engineering Symposium (MIES). Colombo: IEEE.

Reiner, G. and Trcka, M. (2004). Customized supply chain design: Problems and alternatives for a production company in the food industry. A simulation based analysis. International Journal of Production Economics, 89(2), pp.217-229.

Terzi, S. and Cavalieri, S. (2004). Simulation in the supply chain context: a survey. Computers in Industry, 53(1), pp.3-16.

Truong, T. and Azadivar, F. (2003). Simulation optimization in manufacturing analysis: Simulation based configuration for supply chain network design. In: Winter Simulation Conference. pp.1268-1275.

Van Der Vorst, J., Tromp, S. and Zee, D. (2009). Simulation modelling for food supply chain redesign; integrated decision making on product quality, sustainability and logistics. International Journal of Production Research, 47(23), pp.6611-6631.

Varasteh, F. (2007). Using Genetic Algorithm for Supply Chain Network Optimization. pp.01-06. Available at: https://www.researchgate.net/publication/228551885 _Using_Genetic_Algorithm_for_Supply_Chain_Net work_Optimization [Accessed 16 Mar. 2017]. 